\title{
Natural orifice transluminal endoscopic surgery (NOTES): where are we going? A bibliometric assessment
}

\author{
Riccardo Autorino*†, Rachid Yakoubi*, Wesley M. White ${ }^{\ddagger}$, Matthew Gettman§, \\ Marco De Sio ${ }^{\dagger}$, Carmelo Quattrone ${ }^{\dagger}$, Carmine Di Palma ${ }^{\dagger}$, Alessandro Izzo ${ }^{\dagger}$, \\ Jeorge Correia-Pinto", Jihad H. Kaouk* and Estevão Lima"
}

* Glickman Urological and Kidney Institute, Cleveland Clinic, Cleveland, OH, USA, 'Urology Unit, Second University of Naples, Naples, Italy, ${ }^{\ddagger}$ Division of Urologic Surgery, University of Tennessee, Knoxville, TN, and ${ }^{\S}$ Department of Urology, Mayo Clinic, Rochester, MN, USA, and "Life and Health Sciences Research Institute, University of Minho, Braga, Portugal

\section{What's known on the subject? and What does the study add?}

- The safe and successful development of NOTES has the potential to create a paradigm shift in minimally invasive surgery. However, anecdotal diagnostic and therapeutic NOTES procedures, many of which were strictly performed in an investigative fashion, have taught us that continued, focused translational research is imperative to address myriad, and as yet unaddressed, technical issue.

- This study analyses the NOTES-related research in the medical literature over the last 5 years in an attempt to identify trends and/or progress towards its meaningful use. It shows that NOTES is still in a developmental stage and much work is still needed to refine techniques, verify safety and document efficacy. Since the first description of the concept of NOTES, >2000 clinical cases, irrespective of specialty, have been reported. NOTES remains a field of intense clinical and experimental research in various surgical specialties.

The aim of this study was to analyse natural orifice transluminal endoscopic surgery (NOTES)-related publications over the last 5 years. A systematic literature search was done to retrieve publications related to NOTES from 2006 to 2011. The following variables were recorded: year of publication; article type; study design; setting; Journal Citation Reports ${ }^{\circledR}$ journal category; authors area of surgical speciality; geographic area of origin; surgical procedure; NOTES technique; NOTES access route; number of clinical cases. A time-trend analysis was performed by comparing early (2006-2008) and late (2009-2011) study periods.

Overall, 644 publications were included in the analysis and most papers were found in general surgery journals (50.9\%). Studies were most frequently clinical series (43.9\%) and animal experimental (48\%), with the articles focusing primarily on cholecystectomy, access creation and closure, and peritoneoscopy. Pure NOTES techniques were performed in most of the published reports (85\%) with the remaining cases being hybrid NOTES $(7.4 \%)$ and NOTES-assisted procedures (6.1\%). The access routes included transgastric (52.5\%), transcolonic (12.3\%), transvesical (12.5\%), transvaginal (10.5\%), and combined (12.3\%). From the early to the late period, there was a significant increase in the number of randomised controlled trials (5.6\% vs $7.2 \%)$ or non-randomised but comparative studies $(5.6 \%$ vs $22.9 \%)(P<0.001)$ and there was also a significant increase in the number of colorectal procedures and nephrectomies $(P=0.002)$. Pure NOTES remained the most studied approach over the years but with increased investigation in the field of NOTES-assisted techniques $(P=$ $0.001)$. There was also a significant increase in the adoption of transvesical access (7\% vs $15.6 \%)(P=0.007)$. NOTES is in a developmental stage and much work is still needed to refine techniques, verify safety and document efficacy. Since the first description of the concept of NOTES, >2000 clinical cases, irrespective of specialty, have been reported. NOTES remains a field of intense clinical and experimental research in various surgical specialities.

\section{Keywords}

natural orifice transluminal endoscopic surgery, NOTES, trends, urology 


\section{Introduction}

Natural orifice transluminal endoscopic surgery (NOTES) uses transvisceral access to the peritoneal cavity through the mouth, colon, urinary tract, and/or vagina. By accessing the target surgical organ in this fashion, skin incisions can be largely or completely avoided. The safe and successful development of NOTES has the potential to create a paradigm shift in minimally invasive surgery. However, anecdotal diagnostic and therapeutic NOTES procedures, many of which were strictly performed in an investigative fashion, have taught us that continued, focused translational research is imperative to address myriad, and as yet unaddressed, technical issues [1-5].

Given the intense interest in NOTES and its potential to revolutionise current surgical therapy, several working groups have been formed to help guide NOTES research and clinical development. Among them, the Natural Orifice Surgery Consortium for Assessment and Research (NOSCAR) published a landmark 'white paper' in 2006 outlining the perceived barriers to the clinical adoption of NOTES [6]. Since then, there has been a plethora of reports in the field, and some progress has been made in addressing the issues originally set forth by the NOSCAR committee. Germane to urology, investigators have combined natural orifice access with traditional laparoscopic approaches, the so-called hybrid NOTES or NOTES-assisted techniques [7-11]. Initial success with these hybrid procedures emboldened investigators to successfully complete several 'pure' NOTES procedures. Despite successfully performing 'pure' NOTES, the technique remains highly challenging and the pragmatism of its use remains speculative [12].

The aim of the present study was to analyse the NOTES-related research in the medical literature over the last 5 years in an attempt to identify trends and/or progress towards meaningful use.

\section{Materials and Methods}

A systematic literature search was done by using PubMed to retrieve publications related to NOTES from 2006 to 2011. The search terms used were: 'natural orifice transluminal endoscopic surgery' and 'NOTES'. A hand search of article references was done to ensure that all publications on this topic were found. Four independent reviewers screened the studies for eligibility. Final consensus on study selection was achieved by discussion between the reviewers and arbitration by the lead investigator.

The following variables were recorded: year of publication; article type; study design; setting; Journal Citation Reports® (JCR) journal category; authors area of surgical speciality; geographic area of origin; surgical procedure; NOTES technique; NOTES access route; number of clinical cases.

For descriptive statistics, the data are presented as frequencies (percentages) or median (range) and mean (SD). A time-trend analysis was performed by comparing early (2006-2008) and late (2009-2011) study periods. Intergroup comparison was done using the nonparametric Mann-Whitney $U$-test for continuous variables and the chi-square test for categorical data. A two-sided $P<0.05$ was considered to indicate statistical significance.

\section{Results}

Overall, 644 publications were identified (55.6\% original articles, $32 \%$ reviews, $12.4 \%$ case reports) and included in the analysis (Table 1). Most of the papers were found in general surgery journals (50.9\%) with urology journals reporting $9.9 \%$ of them. Papers originated mostly from the USA (42.9\%) and Europe (37.4\%). Studies were most frequently clinical (43.9\%) and animal experimental (48\%) series. The articles focused primarily on cholecystectomy, access creation and closure, and peritoneoscopy. Pure NOTES techniques were performed in most of the published reports $(85 \%)$ with the remaining cases being hybrid NOTES (7.4\%) and NOTES-assisted procedures (6.1\%). Access routes included transgastric (52.5\%), transcolonic (12.3\%), transvesical (12.5\%), transvaginal (10.5\%), and combined (12.3\%).

Over the 5-year period there has been a steady increase in the number of NOTES publications, both in the experimental and clinical setting. There was a reasonable balance between original studies and review articles (Fig. 1).

From the early (2006-2008) to the late (2009-2011) period, there was a significant increase in the number of clinical cases reported per article ( 2 vs $6, P=0.008$ ) and a significant increase in the number of randomised controlled trials (RCTs, $5.6 \%$ vs $7.2 \%$ ) or non-randomised but comparative studies ( $5.6 \%$ vs $22.9 \%, P<0.001)$. There was no significant difference in the type of article and/or setting between the two time periods. However, we did witness a significant increase in the number of NOTES publications within urology journals between the early and late time periods $(7.1 \%$ vs $11.8 \%, P=0.002)$ (Table 2$)$. Most of the studies in the early time period originated from the USA while European investigators contributed most of the articles in the late time period $(P<0.001)$. For the reported procedures, there was a significant increase in the number of colorectal procedures and nephrectomies $(P=0.002)$. Pure NOTES remained the most studied approach over the years but with increased investigation in the field of 
Table 1 Descriptive data.

\begin{tabular}{|c|c|}
\hline Variable (overall number) & Value \\
\hline \multicolumn{2}{|l|}{ Time period $(n=644), n(\%)$} \\
\hline $2006-08$ & $255(39.6)$ \\
\hline 2009-11 & $389(60.4)$ \\
\hline \multicolumn{2}{|l|}{ Article type $(n=644), n(\%)$} \\
\hline Original article & $358(55.6)$ \\
\hline Case report & $80(12.4)$ \\
\hline Review/consensus & $206(32.0)$ \\
\hline \multicolumn{2}{|l|}{ Study design $(n=361), n(\%)$} \\
\hline RCT & $24(6.6)$ \\
\hline Non-randomised comparative & $61(16.9)$ \\
\hline Case series & $276(76.5)$ \\
\hline \multicolumn{2}{|l|}{ Setting $(n=487), n(\%)$} \\
\hline Clinical & $214(43.9)$ \\
\hline Experimental dry laboratory & $15(3.1)$ \\
\hline Experimental animal laboratory & $234(48.0)$ \\
\hline Experimental cadaver laboratory & $15(3.1)$ \\
\hline$\geq 2$ settings & $9(1.8)$ \\
\hline \multicolumn{2}{|l|}{ JCR journal category $(n=644), n(\%)$} \\
\hline Gastroenterology and hepatology & $207(32.1)$ \\
\hline Surgery & $328(50.9)$ \\
\hline Urology and nephrology & $64(9.9)$ \\
\hline Others & $45(7.0)$ \\
\hline \multicolumn{2}{|l|}{ Author speciality $(n=644), n(\%)$} \\
\hline Gastroenterology & $102(15.8)$ \\
\hline Surgery & $391(60.7)$ \\
\hline Urology & $64(9.9)$ \\
\hline Endoscopic surgery & $40(6.2)$ \\
\hline Others & $47(7.3)$ \\
\hline \multicolumn{2}{|l|}{ Origin $(n=629), n(\%)$} \\
\hline Europe & $235(37.4)$ \\
\hline USA & $270(42.9)$ \\
\hline Other & $124(19.7)$ \\
\hline \multicolumn{2}{|l|}{ Surgical procedure $(n=422), n(\%)$} \\
\hline Cholecystectomy & $77(18.2)$ \\
\hline Access & $67(15.9)$ \\
\hline Others general surgery & $56(13.3)$ \\
\hline Peritoneoscopy & $53(12.6)$ \\
\hline Gastric surgery & $52(12.3)$ \\
\hline Colorectal resection & $41(9.7)$ \\
\hline Nephrectomy & $26(6.2)$ \\
\hline Thoracoscopy & $23(5.5)$ \\
\hline Appendectomy & $9(2.1)$ \\
\hline Others urology & $9(2.1)$ \\
\hline Gynaecology procedures & $9(2.1)$ \\
\hline \multicolumn{2}{|l|}{ Technique $(n=618), n(\%)$} \\
\hline NOTES & $525(85.0)$ \\
\hline Hybrid NOTES & $46(7.4)$ \\
\hline NOTES-assisted laparoscopy & $38(6.1)$ \\
\hline$>1$ technique & $9(1.5)$ \\
\hline \multicolumn{2}{|l|}{ Access route $(n=400), n(\%)$} \\
\hline Trangastric/transoesophageal & $210(52.5)$ \\
\hline Transcolonic/transanal & $49(12.3)$ \\
\hline Transvaginal & $42(10.5)$ \\
\hline Transvesical & $50(12.5)$ \\
\hline$>1$ access & $49(12.3)$ \\
\hline \multicolumn{2}{|l|}{ Number of clinical cases $(n=105)$} \\
\hline Pure NOTES, $n(\%)$ & $1286(55.7)$ \\
\hline Hybrid NOTES, $n(\%)$ & $632(27.3)$ \\
\hline NOTES-assisted, $n$ (\%) & $201(8.7)$ \\
\hline$>1$ technique, $n(\%)$ & $190(8.2)$ \\
\hline Total, $n$ & 2309 \\
\hline Median (range) number per article & $5(1-362)$ \\
\hline Mean (SD) number per article & $22(47.7)$ \\
\hline
\end{tabular}

Fig. 1 a, Cumulative incidence of papers published by setting; b. Cumulative incidence of papers published by type of article.

a
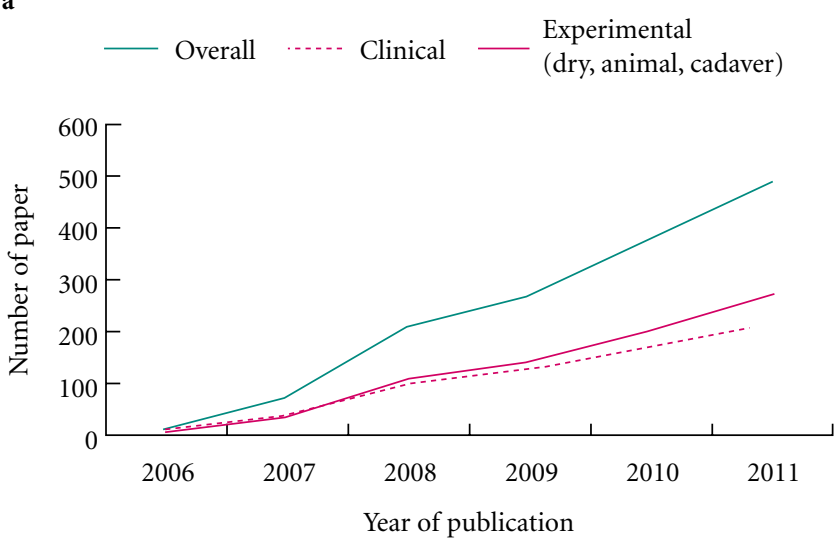

b
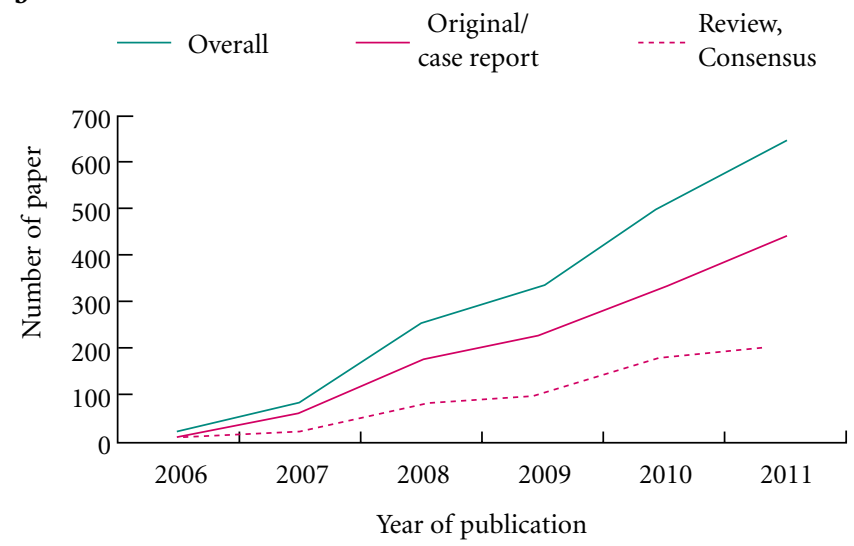

NOTES-assisted techniques $(P=0.001)$. Finally, there was a significant increase in the adoption of transvesical access (7\% vs $15.6 \%, P=0.007)$.

\section{Discussion}

The development and implementation of NOTES is an excellent example of how a multi-disciplinary approach to research can and should foster non-summative results. In 2005, a working group named NOSCAR, composed of members from the Society of American Gastrointestinal and Endoscopic Surgeons and the American Society for Gastrointestinal Endoscopy, was established. This working group generated a white paper that encouraged future NOTES research and outlined key research areas that needed to be addressed [6]. Two years later, the Endourological Society endorsed a NOTES working group that was charged with increasing awareness about 'scarless' surgery, to further define nomenclature germane to NOTES, to guide scientific evaluation, and to provide opportunities for safe clinical implementation of NOTES urological procedures [13]. In 2010, the European Society 
Table 2 Comparison between the two time periods.

\begin{tabular}{|c|c|c|c|}
\hline \multirow[t]{2}{*}{ Variable } & \multicolumn{2}{|c|}{ Period } & \multirow[t]{2}{*}{$\boldsymbol{P}$} \\
\hline & $2006-2008$ & $2009-2011$ & \\
\hline Study design, $n(\%)$ & & & $<0.001$ \\
\hline RCT & $7(5.6)$ & $17(7.2)$ & \\
\hline Non-randomised comparative & $7(5.6)$ & $54(22.9)$ & \\
\hline Case series & $111(88.8)$ & $165(69.9)$ & \\
\hline Article type, $n(\%)$ & & & 0.563 \\
\hline Original article & $138(54.1)$ & $220(56.6)$ & \\
\hline Case report & $36(14.1)$ & $44(11.3)$ & \\
\hline Review, consensus & $81(31.8)$ & $125(32.1)$ & \\
\hline Setting, $n(\%)$ & & & 0.073 \\
\hline Clinical & $102(48.6)$ & $112(40.4)$ & \\
\hline Other setting & $108(51.4)$ & $165(59.6)$ & \\
\hline JCR Journal category, $n(\%)$ & & & 0.002 \\
\hline Gastroenterology and hepatology & $99(38.8)$ & $108(27.8)$ & \\
\hline Surgery & $128(50.2)$ & $200(51.4)$ & \\
\hline Urology and nephrology & $18(7.1)$ & $46(11.8)$ & \\
\hline Others & $10(3.9)$ & $35(9.0)$ & \\
\hline Author speciality, $n$ (\%) & & & $<0.001$ \\
\hline Gastroenterology & $38(14.9)$ & $64(16.5)$ & \\
\hline Surgery & $159(62.4)$ & $232(59.6)$ & \\
\hline Urology & $18(7.1)$ & $46(11.8)$ & \\
\hline Endoscopic surgery & $31(12.2)$ & $9(2.3)$ & \\
\hline Others & $9(3.5)$ & $38(9.8)$ & \\
\hline Origin, $n(\%)$ & & & $<0.001$ \\
\hline Europe & $76(31.4)$ & $159(41.1)$ & \\
\hline USA & $134(55.4)$ & $136(35.1)$ & \\
\hline Other & $32(13.2)$ & $92(23.8)$ & \\
\hline Procedure, $n(\%)$ & & & 0.002 \\
\hline Cholecystectomy & $28(18.1)$ & $49(18.4)$ & \\
\hline Colorectal resection & $9(5.8)$ & $32(12.0)$ & \\
\hline Gastric surgery & $18(11.6)$ & $34(12.7)$ & \\
\hline Peritoneoscopy & $32(20.6)$ & $21(7.9)$ & \\
\hline Nephrectomy & $7(4.5)$ & $19(7.1)$ & \\
\hline Access (closure, creation) & $29(18.7)$ & $38(14.2)$ & \\
\hline Others & $32(20.6)$ & $74(27.7)$ & \\
\hline Technique, $n$ (\%) & & & 0.001 \\
\hline NOTES & $221(90.6)$ & $304(81.3)$ & \\
\hline Hybrid NOTES & $17(7.0)$ & $29(7.8)$ & \\
\hline NOTES-assisted laparoscopy & $6(2.5)$ & $32(8.6)$ & \\
\hline$>1$ technique & 0 & $9(2.4)$ & \\
\hline Access route, $n(\%)$ & & & 0.007 \\
\hline Trangastric/transoesophagueal & $77(53.8)$ & $133(51.8)$ & \\
\hline Transcolonic/transanal & $16(11.2)$ & $33(12.8)$ & \\
\hline Transvaginal & $24(16.8)$ & $18(7.0)$ & \\
\hline Transvesical & $10(7.0)$ & $40(15.6)$ & \\
\hline$>1$ access, or other access & $16(11.2)$ & $33(12.8)$ & \\
\hline Number of clinical cases & & & 0.008 \\
\hline MEDIAN (range) & $2(1-50)$ & $6(1-362)$ & \\
\hline MEAN (SD) & $7.2(11.7)$ & $28.1(55.2)$ & \\
\hline
\end{tabular}

of Urotechnology similarly formed a working group dedicated to 'scarless' techniques and more recently a joint consensus statement of both working groups was published [14]. The aforementioned consensus statement stressed that NOTES should be cautiously implemented clinically and only in the setting of an active Institutional Review Board-approved study. These recommendations were made with full appreciation of recent successful NOTES procedures including the successful clinical completion of a transvaginal NOTES nephrectomy and of transurethral NOTES radical prostatectomies $[12,15]$.
The present literature analysis provides an articulate overview of what has been done to date in the field of NOTES, both experimentally and clinically. A few salient conclusions can be drawn.

First, there has been a steady increase in the number of NOTES publications over the past 5 years with the plurality being original articles reporting case series. Not surprisingly, few RCTs have been reported. Thus, there remains a paucity of high-level evidence to support anything beyond the feasibility of these procedures. 
Certainly, no conclusions can be drawn about the overall safety, efficacy, and/or superiority of the approach [3]. However, our research did note an overall increase in the number of comparative studies, including RCTs, within the last several years. This may be viewed optimistically as an expected step towards a higher level of evidence.

Second, most NOTES publications have largely been submitted to journals within the gastroenterology and general surgical fields. This matches with the specialty of the authors and the fact that most reported series have focused on cholecystectomy, peritoneoscopy, and gastric surgery [6]. Certainly, cholecystectomy represents the most approachable procedure for NOTES, given its accessibility and comparative simplicity. Conversely, only $10 \%$ of NOTES publications have focused on urological topics. Again, this is consistent with the comparative complexity of most urological procedures and the difficulty in accessing the retroperitoneum through a transvisceral route. The most commonly reported NOTES urological procedure has thus far been simple or radical nephrectomy. This is explained, in part, by the completely extirpative nature of the operation. This resembles what has been reported for laparoendoscopic single-site surgery, the other 'scarless' technique, where the most commonly performed procedure worldwide has been nephrectomy as well [16]. Despite the seemingly straight-forward nature of the operation, successful completion of NOTES nephrectomy has remained sparse. Indeed, most NOTES nephrectomies in humans have been hybrid procedures [1] with only one 'pure' transvaginal nephrectomy thus far reported [12].

Third, when looking at the entire NOTES literature, 'pure' NOTES procedures actually represent the most frequently reported (85\% of the cases) approach. For the preferred route of access, investigators have focused on the transgastric/transoesophageal route $(52.5 \%)$ or a combination of access routes. This obviously dovetails with our aforementioned findings about surgical type and surgeon specialty. And as investigators have become more confident with simply achieving access and performing diagnostic and straight-forward extirpative procedures (cholecystectomy), we have also seen a manifold increase in the number and variety of reported cases of extirpative procedures, e.g. colorectal surgery.

Finally, we noted myriad trends within the field of NOTES urological surgery. Urologists have been in the forefront of developing and applying the transvaginal route. Vaginal extraction of an intact kidney after laparoscopic radical nephrectomy was first described by Breda et al. [17] in 1993 and the first experimental NOTES procedure in urology was reported in 2002 by Gettman et al. [18], who described successful transvaginal nephrectomies in pigs. This work predated the first recognised NOTES report on transgastric peritoneoscopy by Kalloo et al. [19] in the gastroenterology literature. Later, another NOTES portal, the bladder, was described for the first time by Lima et al. [20] in a porcine model.

Regarding the technique, there was an increase in the use of NOTES-assisted laparoscopy techniques. Because of the current limitations and challenges of NOTES, investigators are stepping towards 'scarless' surgery by postulating that laparoscopy, or ultimately mini-laparoscopy, and NOTES complementary and their combination allows performance of a procedure that is technically similar to a standard laparoscopic procedure, simpler than pure NOTES, with the advantages of using a natural orifice [11].

Finally, it was interesting to see that, among the NOTES routes, that the transvesical one has received much attention over the last few years. This route potentially provides several advantages as it is naturally sterile, it provides a favourable location by allowing peritoneal access above the bowel loops, it allows the introduction of rigid instruments and it is of course available in both genders. Of course, disadvantages have been also recognised and they remain to be addressed [11,21].

NOTES is in a developmental stage and much work is still needed to refine techniques, verify safety and document efficacy. However, since the first description of the concept of NOTES, >2000 clinical NOTES cases, irrespective of specialty, have been reported. Such volume is a testament to the commitment of investigators worldwide to prove even more than the feasibility of this novel surgical concept. Despite significant residual challenges related to its development and several open issues, NOTES remains a field of intense clinical and experimental research in various surgical specialities, including urology.

\section{Conflict of Interest}

None declared.

\section{References}

1 Autorino R, Haber GP, White MA et al. Pure and hybrid natural orifice transluminal endoscopic surgery (NOTES): current clinical experience in urology. BJU Int 2010; 106: 919-22

2 Lima E, Rolanda C, Autorino R, Correia-Pinto J. Experimental foundation for natural orifice transluminal endoscopic surgery and hybrid natural orifice Transluminal endoscopic surgery. BJU Int 2010; 106: 913-8

3 Autorino R, Cadeddu JA, Desai MM et al. Laparoendoscopic single-site and natural orifice transluminal endoscopic surgery in urology: a critical analysis of the literature. Eur Urol 2011; 59: 26-45 
4 White WM, Haber GP, Doerr MJ, Gettman M. Natural orifice translumenal endoscopic surgery. Urol Clin North Am 2009; 36: 147-55

5 Gettman MT, Cadeddu JA. Natural orifice translumenal endoscopic surgery (NOTES) in urology: initial experience. J Endourol 2008; 22: 783-8

6 Rattner D, Kalloo A, ASGE/SAGES Working Group. ASGE/SAGES Working Group on Natural Orifice Translumenal Endoscopic Surgery. October 2005. Surg Endosc 2006; 20: 329-33

7 Branco AW, Branco Filho AJ, Kondo W et al. Hybrid transvaginal nephrectomy. Eur Urol 2008; 53: 1290-4

8 Alcaraz A, Peri L, Molina A et al. Feasibility of transvaginal NOTES-assisted laparoscopic nephrectomy. Eur Urol 2010; 57: 233-7

9 Kaouk JH, White WM, Goel RK et al. NOTES transvaginal nephrectomy: first human experience. Urology 2009; 74: 5-8

10 Sotelo R, de Andrade R, Fernandez G et al. NOTES hybrid transvaginal radical nephrectomy for tumor: stepwise progression toward a first successful clinical case. Eur Urol 2010; 57: 138-44

11 Porpiglia F, Fiori C, Morra I, Scarpa RM. Transvaginal natural orifice transluminal endoscopic surgery-assisted minilaparoscopic nephrectomy: a step towards scarless surgery. Eur Urol 2011; 60: 862-6

12 Kaouk JH, Haber GP, Goel RK et al. Pure natural orifice translumenal endoscopic surgery (NOTES) transvaginal nephrectomy. Eur Urol 2010; 57: 723-6

13 Gettman MT, Box G, Averch T et al. Consensus statement on natural orifice transluminal endoscopic surgery and single-incision laparoscopic surgery: heralding a new era in urology? Eur Urol 2008; 53: 1117-20

14 Gettman MT, White WM, Aron M et al. Where do we really stand with LESS and NOTES? Eur Urol 2011; 59: 231-4
15 Humphreys MR, Sauer JS, Ryan AR et al. Natural orifice transluminal endoscopic radical prostatectomy: initial perioperative and pathologic results. Urology 2011; 78: 1211-7

16 Kaouk JH, Autorino R, Kim FJ et al. Laparoendoscopic single-site surgery in urology: worldwide multi-institutional analysis of 1076 cases. Eur Urol 2011; 60: 998-1005

17 Breda G, Silvestre P, Giunta A, Xausa D, Tamai A, Gherardi L. Laparoscopic nephrectomy with vaginal delivery of the intact kidney. Eur Urol 1993; 24: 116-7

18 Gettman MT, Lotan Y, Napper CA, Cadeddu JA. Transvaginal laparoscopic nephrectomy: development and feasibility in the porcine model. Urology 2002; 59: 446-50

19 Kalloo AN, Singh VK, Jagannath SB et al. Flexible transgastric peritoneoscopy: a novel approach to diagnostic and therapeutic interventions in the peritoneal cavity. Gastrointest Endosc 2004; 60: 114-7

20 Lima E, Rolanda C, Pêgo J et al. Transvesical endoscopic peritoneoscopy: a novel $5 \mathrm{~mm}$ port for intra-abdominal scarless surgery. J Urol 2006; 176: $802-5$

21 Lima E, Autorino R, Correia-Pinto J. Transvesical endoscopic port in abdominal surgery: an updated perspective. Curr Urol Rep 2010; 11: 128-31

Correspondence: Riccardo Autorino, Glickman Urological and Kidney Institute, Cleveland Clinic, 9500 Euclid Avenue, Cleveland, OH 44195, USA.

e-mail: ricautor@tin.it; autorir@ccf.org

Abbreviations: JCR, Journal Citation Reports®; NOSCAR, Natural Orifice Surgery Consortium for Assessment and Research; NOTES, natural orifice transluminal endoscopic surgery; RCT, randomised controlled trials. 